\title{
PENGARUH KUALITAS PRODUK DAN KUALITAS PELAYANAN TERHADAP KEPUASAN KONSUMEN PT. RADEKATAMA PIRANTI NUSA
}

\author{
Rosa Lesmana*) \\ Ratnasari**) \\ email:rosa.sunardi@gmail.com
}

\begin{abstract}
Abstrak
Penelitian ini bertujuan untuk mengetahui pengaruh kualitas produk dan kualitas pelayanan terhadap kepuasan konsumen PT. Radekatama Piranti Nusa. Penelitian ini menggunakan metode asosiatif deskriptif dengan pendekatan kuantitatif. Populasinya adalah konsumen yang melakukan pembelian selama tahun 2017 sebanyak 638 konsumen dan sampel diambil sebanyak 86 orang. Perhitungan menggunakan SPSS. Hasil penelitian menunjukkan bahwa kualitas produk dan kualitas pelayanan berpengaruh positif terhadap kepuasan pelanggan dengan persamaan regresi $Y=15,009+0,294 X 1+0,422 X 2$. Kontribusi pengaruh kualitas produk, kualitas pelayanan dan kepuasan pelanggan secara simultan adalah sebesar 44,8\%, nilai $\mathrm{F}$ hitung lebih besar dari $\mathrm{F}$ tabel atau $(39,285>$ 2,700 ), dengan signifikansi $0,000<0,05$.terdapat pengaruh positif dan signifikan secara simultan antara kualitas produk dan kualitas pelayanan terhadap kepuasan konsumen.
\end{abstract}

\begin{abstract}
This study aims to determine the effect of product quality and service quality on customer satisfaction PT. Radekatama Piranti Nusa. This study uses a descriptive associative method with a quantitative approach. The population is consumers who made purchases in 2017 as many as 638 consumers and samples taken as many as 86 people. Calculation using SPSS. The results showed that product quality and service quality had a positive effect on customer satisfaction with the regression equation $Y=15.009+0.294 X 1+$ $0.422 X 2$. The contribution of product quality, service quality and customer satisfaction simultaneously is $44.8 \%$, the calculated $F$ value is greater than $F$ table or $(39.285>2,700)$, with a significance of $0,000<0,05$. There is a simultaneous positive and significant influence between product quality and service quality to customer satisfaction.
\end{abstract}

Key Word : Product quality, service quality, customer satisfaction

\section{A. Latar Belakang Masalah}

PT. Radekatama Piranti Nusa menyadari dan berusaha untuk memberikan nilai-nilai yang diharapkan pelanggan dan bahkan memberikan lebih dari apa yang pelanggan harapkan. Apabila kepuasan pelanggan menurun akan mengakibatkan jumlah pendapatan juga menurun.

Berikut ini data penjualan PT. Radekatama Piranti Nusa Tahun 2013 sampai dengan Tahun 2017 yang dapat dilihsat pada tabel yang tertera dibawah ini : 
Tabel 1

Jumlah Penjualan dan Tingkat Pencapaian Target

PT. Radekatama Piranti Nusa

\begin{tabular}{|c|c|c|c|c|}
\hline \multirow{2}{*}{ Tahun } & Target & Realisasi & $\%$ & keterangan \\
\hline & dalam $(\mathrm{Rp})$ & dalam $(\mathrm{Rp})$ & & \\
\hline 2013 & $\begin{array}{l}35.625 .000 . \\
000\end{array}$ & $\begin{array}{l}30.014 .076 .75 \\
0\end{array}$ & $84 \%$ & tidak melampaui target \\
\hline 2014 & $\begin{array}{l}39.187 .500 . \\
000\end{array}$ & $\begin{array}{l}28.924 .835 .25 \\
0\end{array}$ & $74 \%$ & tidak melampaui target \\
\hline 2015 & $\begin{array}{l}42.750 .000 . \\
000\end{array}$ & $\begin{array}{l}39.025 .648 .50 \\
0\end{array}$ & $91 \%$ & tidak melampaui target \\
\hline 2016 & $\begin{array}{l}46.312 .500 . \\
000\end{array}$ & $\begin{array}{l}42.927 .384 .00 \\
0\end{array}$ & $93 \%$ & tidak melampaui target \\
\hline 2017 & $\begin{array}{l}49.875 .000 . \\
000\end{array}$ & $\begin{array}{l}40.134 .170 .25 \\
0\end{array}$ & $80 \%$ & tidak melampaui target \\
\hline
\end{tabular}

Sumber : Data jumlah penjualan dan pencapaian target pada PT. Radekatama Piranti Nusa, 2018

\section{Grafik 1}

Data Jumlah penjualan

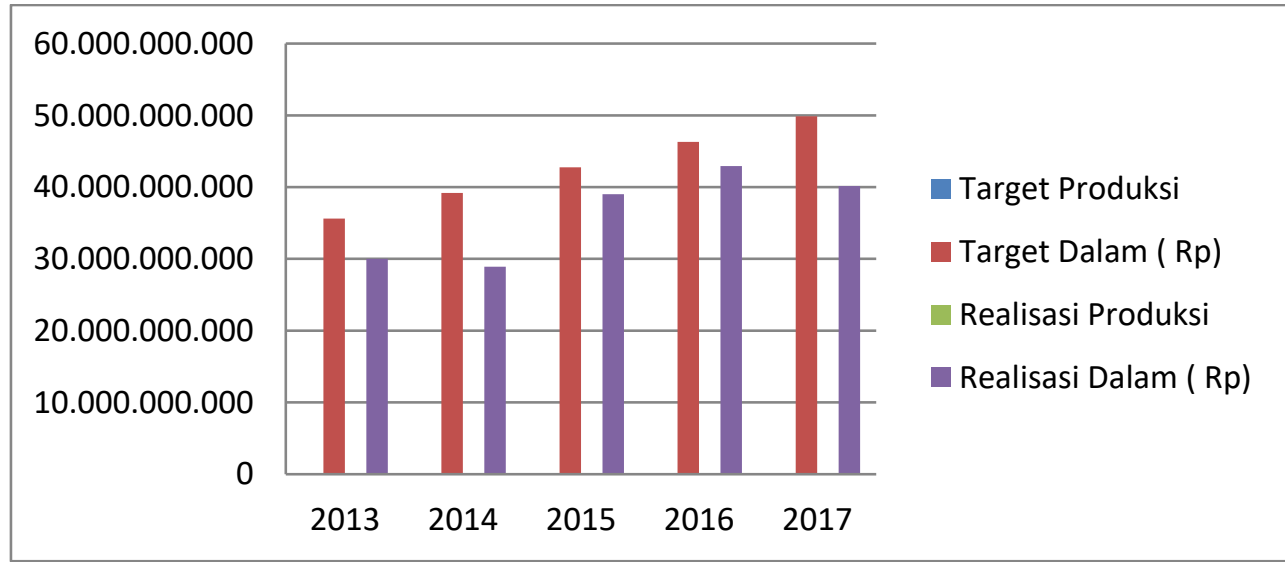

Berdasarkan dari tabel dan grafik 1.1 diatas, memperlihatkan bahwa jumlah penjualan PT. Radekatama Piranti Nusa mengalami perkembangan yang fluktuatif setiap tahunnya.

Tabel 2

Jumlah Keluhan Pelanggan Tahun 2013- 2017

\begin{tabular}{|c|c|c|c|c|c|}
\hline \multirow{3}{*}{ Tahun } & \multicolumn{5}{|c|}{ Jenis Keluhan/Complaint } \\
\cline { 2 - 6 } & $\begin{array}{c}\text { Ketepata } \\
\mathrm{n} \\
\text { Informas } \\
\mathrm{i}\end{array}$ & $\begin{array}{c}\text { Berat } \\
\text { Tabung }\end{array}$ & $\begin{array}{c}\text { Sarana dan } \\
\text { Prasarana }\end{array}$ & $\begin{array}{c}\text { Segel } \\
\text { Rusak }\end{array}$ & Tabung Bocor \\
\hline 2013 & 9 & 11 & 6 & 9 & 10 \\
\hline
\end{tabular}




\begin{tabular}{|c|c|c|c|c|c|}
\hline 2014 & 11 & 12 & 5 & 10 & 12 \\
\hline 2015 & 13 & 9 & 7 & 10 & 11 \\
\hline 2016 & 14 & 11 & 10 & 12 & 12 \\
\hline 2017 & 14 & 12 & 9 & 11 & 13 \\
\hline
\end{tabular}

Sumber : Data jumlah keluhan pelanggan pada PT.Radekatama Piranti Nusa, 2018

Grafik 2

Data Keluhan Pelanggan

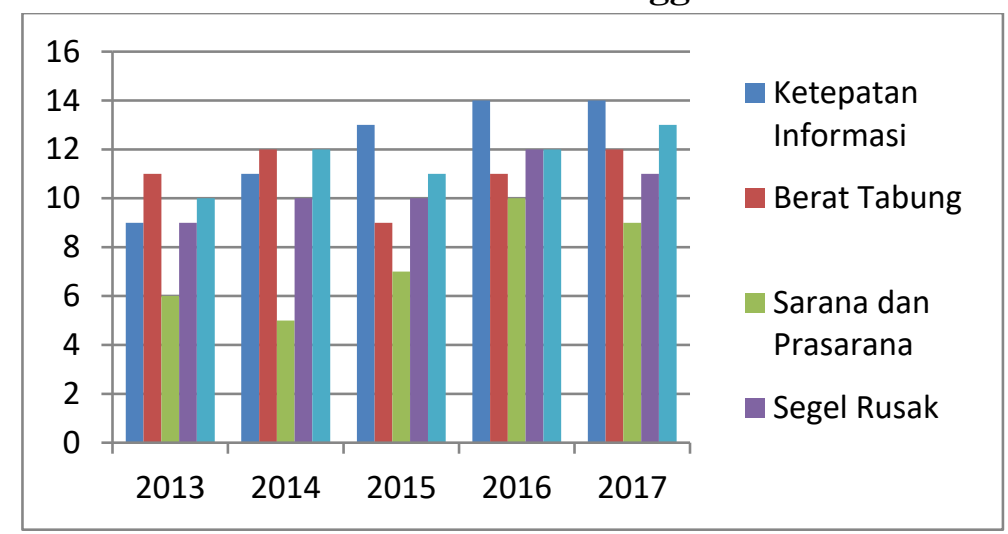

Sumber : Data jumlah keluhan pelanggan pada PT. Radekatama Piranti Nusa, 2018

Adanya peningkatan keluhan pelanggan seperti pada tabel 1.2 diatas mengenai pemberian informasi yang kurang akurat, berat tabung, sarana dan prasarana, segel rusak dan tabung yang bocor yang semakin meningkat, hal ini di khawatirkan dapat mengurangi kepuasan pelanggan.

Berikut ini data jumlah pelanggan PT. Radekatama Piranti Nusa, yaitu sebagai berikut :

\section{Tabel 3}

Jumlah Pelanggan Tahun 2013- 2017

\begin{tabular}{|c|c|c|}
\hline No. & Tahun & Jumlah Pelanggan \\
\hline 1 & 2013 & 121 \\
\hline 2 & 2014 & 116 \\
\hline 3 & 2015 & 138 \\
\hline 4 & 2016 & 126 \\
\hline 5 & 2017 & 137 \\
\hline \multicolumn{3}{|c|}{ Total } \\
\hline
\end{tabular}

Sumber : Data Jumlah pelanggan PT. Radekatama Piranti Nusa

Dari data tabel 1.3 diatas memperlihatkan bahwa jumlah pelanggan mengalami kenaikan yang fluktuatif tiap tahunnya . di Tahun 2013 jumlah 
pelanggan yang dimiliki ialah 121 di Tahun 2014 mengalami penurunan yaitu 116 di Tahun 2015 mengalami kenaikan yaitu 138 di Tahun 2016 mengalami penurunan kembali yaitu 126 jumlah pelanggan dan di Tahun 2017 mengalami kenaikan kembali yaitu 137 pelanggan.

\section{B. Rumusan Masalah}

Berdasarkan latar belakang, identifikasi masalah, dan pembatasan masalah di atas maka dapat di rumuskan suatu permasalahan sebagai berikut:

1. Bagaimana pengaruh kualitas produk terhadap kepuasan pelanggan secara parsial di PT. Radekatama Piranti Nusa?

2. Bagaimana pengaruh kualitas pelayanan terhadap kepuasan pelanggan secara parsial di PT. Radekatama Piranti Nusa?

3. Bagaimana pengaruh kualitas produk dan kualitas pelayanan terhadap kepuasan pelanggan secara simultan di PT. Radekatama Piranti Nusa?

\section{Tujuan Penelitian}

1. Untuk mengetahui pengaruh kualitas produk terhadap kepuasan pelanggan secara parsial di PT. Radekatama Piranti Nusa.

2. Untuk mengetahui pengaruh kualitas pelayanan terhadap kepuasan pelanggan secara parsial di PT. Radekatama Piranti Nusa.

3. Untuk mengetahui pengaruh kualitas produk, kualitas pelayanan terhadap kepuasan pelanggan secara simultan di PT. Radekatama Piranti

\section{Landasan Teori}

Pengertian Kualitas Produk

Menurut Kotler dan Armstrong (2012:299) berpendapat "Kualitas produk adalah kemampuan produk untuk menampilkan fungsinya, hal ini termasuk waktu kegunaan dari produk, keandalan, kemudahan, dalam penggunaan dan perbaikan, dan nilai-nilai yang lainya. Kulaitas produk dapat ditinjau dari dua sudut pandang yaitu sudut pandang internal dan sudut pandang eksternal".

\section{Kualitas Pelayanan}

Menurut Nanang Tasunar (2012:44) mendefinisikan "Kualitas pelayanan sebagai suatu konsep yang secara tepat mewakili inti dari kinerja suatu pelayanan, yaitu perbandingan terhadap excellence (keterandalan) dan sales counter yang dilakukan oleh konsumen".

Menurut Tjiptono ( $2012: 59$ ) mengemukakan bahwa "kualitas pelayanan adalah tingkat keunggulan yang diharapkan dan pengendalian atas tingkat keunggulan tersebut untuk memenuhi keinginan pelanggan".

\section{Kepuasan Pelanggan}

Menurut Yazid (2012:55) berpendapat "Kepuasan pelanggan adalah ketiadaan perbedaan antara harapan yang dimiliki dan unjuk kerja yang senyatanya diterima. Apabila harapan tinggi, sementara unjuk kerjanya biasabiasa saja, kepuasan tidak akan tercapai (sangat mungkin pelanggan akan merasa kecewa. Sebaliknya, apabila unjuk kerja melebihi dari yang diharapkan, kepuasan meningkat". 


\section{E. Metodologi Penelitian}

Perusahaan yang menjadi tempat penelitian ini adalah PT. Radekatama Piranti Nusa dengan alamat Jl. Pamulang II, RT. 003 RW. 001, Pondok BendaPamulang, Tangerang Selatan TLP. (021) 74633012 FAX. (021) 74633051.

Waktu Penelitian ini dilaksanakan selama 3 (tiga) dimulai dari bulan Februari s.d. April 2018.

Populasi dalam penelitian ini adalah semua perusahaan yang menjadi pelanggan PT. Radekatama Piranti Nusa pada tahun 2017 yang berjumlah 638 pelanggan. Sampel menggunakan rumus Slovin (Syofian Siregar, 2014:61) sebanyak 86

Pengujian statistik dilakukan dengan beberapa uji antaralain:

a. Uji Validitas Data

b. Uji Reliabilitas Data

c. Uji Asumsi Klasik (Uji Nomalitas, Uji Multikolonieritas, Uji Autokorelasi)

d. Uji Regresi Linear Berganda

e. Uji Korelasi

f. Uji Determinasi

g. Uji Hipotesis t

h. Uji Hipotesis f

\section{F. Hasil Dan Pembahasan}

Tabel 4.1

Pengujian Validitas Instrumen Pertanyaan Kualitas Produk ( $\left.\mathbf{X}_{1}\right)$

\begin{tabular}{|l|c|c|c|}
\hline \multicolumn{1}{|c|}{ Pernyataan } & r Hitung & $\begin{array}{c}\text { Nilai } \mathbf{r} \\
\text { tabel }\end{array}$ & Keputusan \\
\hline 1. Produk memiliki kualitas baik & 0.582 & 0.210 & Valid \\
\hline 2. Produk dapat bersaing & 0.572 & 0.210 & Valid \\
\hline 3. Didukung mesin yang modern & 0.640 & 0.210 & Valid \\
\hline 4. Produk dapat bertahan lama & 0.566 & 0.210 & Valid \\
\hline 5. Kesesuaian berat tabung & 0.359 & 0.210 & Valid \\
\hline $\begin{array}{l}\text { 6. Kesesuaian dengan standart } \\
\text { pertamina }\end{array}$ & 0.668 & 0.210 & Valid \\
\hline 7. Sesuai dengan kebutuhan & 0.702 & 0.210 & Valid \\
\hline 8. Tarif sesuai dengan manfaat & 0.646 & 0.210 & Valid \\
\hline $\begin{array}{l}\text { 9. Tabung memiliki berat timbangan } \\
\text { sesuai }\end{array}$ & 0.732 & 0.210 & Valid \\
\hline 10. Tabung dilengkapi seal cap & 0.676 & 0.210 & Valid \\
\hline
\end{tabular}

Sumber : Hasil Pengolahan Data, 2018. 
Tabel 4.2

Pengujian Validitas Instrumen Pertanyaan Kualitas Pelayanan (X2)

\begin{tabular}{|l|c|c|c|}
\hline \multicolumn{1}{|c|}{ Pernyataan } & $\begin{array}{c}\mathbf{r} \\
\text { hitung }\end{array}$ & $\begin{array}{c}\text { Nilai } \\
\text { r table }\end{array}$ & Keputusan \\
\hline 1. Penampilan karyawan sopan & 0.254 & 0.210 & Valid \\
\hline 2. Area pabrik dan kantor bersih & 0.497 & 0.210 & Valid \\
\hline 3. Pelayanan petugas selalu baik & 0.383 & 0.210 & Valid \\
\hline 4. Ketepatan informasi & 0.495 & 0.210 & Valid \\
\hline 5. Kecepatan merespon & 0.457 & 0.210 & Valid \\
\hline 6. Ketanggapan pelayanan & 0.481 & 0.210 & Valid \\
\hline 7. Pelayanan tepat waktu & 0.679 & 0.210 & Valid \\
\hline 8. Jaminan Produk sesuai & 0.623 & 0.210 & Valid \\
\hline 9. Perhatian kepada pelanggan & 0.478 & 0.210 & Valid \\
\hline 10.Jaminan produk sesuai ukuran & 0.314 & 0.210 & Valid \\
\hline
\end{tabular}

Sumber : Hasil Pengolahan Data, 2018.

Tabel 4.3

Pengujian Validitas Instrumen Pertanyaan Kepuasan Pelanggan (Y)

\begin{tabular}{|c|c|c|c|}
\hline Pernyataan & $\begin{array}{c}\mathbf{r} \\
\text { hitung }\end{array}$ & $\begin{array}{c}\text { Nilai r } \\
\text { tabel }\end{array}$ & Keputusan \\
\hline 1. Memberikan rasa nyaman & 0.615 & 0.210 & Valid \\
\hline 2. Dapat memenuhi keinginan & 0.645 & 0.210 & Valid \\
\hline 3. Dapat memenuhi kebutuhan & 0.408 & 0.210 & Valid \\
\hline 4. Ketepatan pengadaan barang & 0.562 & 0.210 & Valid \\
\hline 5. Produk susah tergantikan & 0.612 & 0.210 & Valid \\
\hline 6 Tidak berniat membeli dari Sppbe lain & 0.747 & 0.210 & Valid \\
\hline 7. Merekomendasikan ke orang lain & 0.392 & 0.210 & Valid \\
\hline 8. Senang melakukan kerja sama & 0.612 & 0.210 & Valid \\
\hline 9. Memberikan kritik dan saran & 0.457 & 0.210 & Valid \\
\hline 10. Mendorong melakukan inovasi produk & 0.653 & 0.210 & Valid \\
\hline
\end{tabular}

Sumber : Hasil Pengolahan Data, 2018. 
Dari data tabel di atas, variabel Kepuasan pelanggan $(\mathrm{Y})$ diperoleh nilai $r$ hitung lebih besar dari 0,210 atau ( $\left.r_{\text {hitung }}>r_{\text {tabel }}\right)$, semua item pernyataan dinyatakan valid, kuesioner yang digunakan layak untuk diolah sebagai data penelitian.

Tabel 4.4

Hasil Pengujian Reliabilitas Variabel Independen dan Variabel Dependen

\begin{tabular}{|l|c|c|c|}
\hline Variabel & $r$ hitung & $r$ table & Keputusan \\
\hline Kualitas Produk (X1) & 0.815 & 0.210 & Reliabel \\
Kualitas Pelayanan (X2) & 0.596 & 0.210 & Reliabel \\
Kepuasan Pelanggan (Y) & 0.763 & 0.210 & Reliabel \\
\hline
\end{tabular}

Sumber : Hasil Pengolahan Data, 2018.

Berdasarkan tabel di atas, menunjukkan bahwa semua item pertanyaan variabel kualitas produk $\left(\mathrm{X}_{1}\right)$ kualitas pelayanan $\left(\mathrm{X}_{2}\right)$ dan kepuasan pelanggan $(\mathrm{Y})$ dinyatakan reliabel, hal itu dibuktikan dengan nilai $r$ hitung lebih besar dari 0,210 atau ( $\left.r_{\text {hitung }}>r_{\text {tabel }}\right)$.

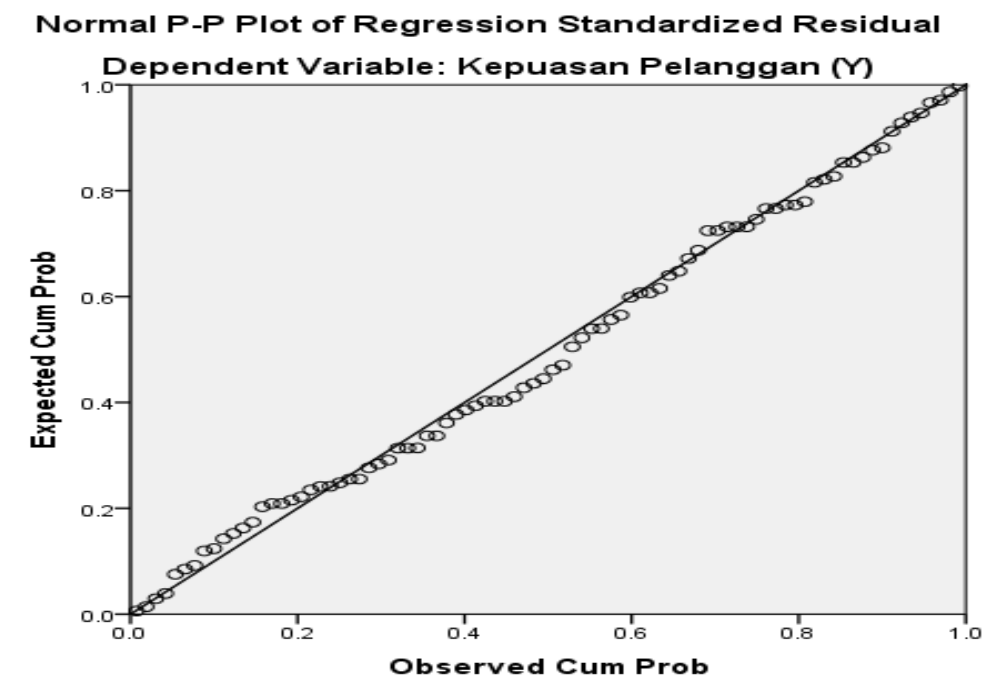

Sumber : Data Primer, tahun 2018 diolah

Gambar 4.1

P-P Plot Uji Normalitas - Diagram Penyebaran Titik Residual

Tabel 4.5

Hasil Pengujian Multikolinearitas Dengan Collinearity Statistic Kepuasan Pelanggan Sebagai Variabel Dependen 


\begin{tabular}{|l|c|c|c|c|l|}
\hline \multicolumn{1}{|c|}{ Variabel } & $\begin{array}{c}\text { Nilai } \\
\text { Tolerance }\end{array}$ & Ketetapan & $\begin{array}{c}\text { Nilai } \\
\text { VIF }\end{array}$ & Ketetapan & \multicolumn{1}{|c|}{ Kriteria } \\
\hline Kualitas Produk $\left(\mathrm{X}_{1}\right.$ & 0.960 & $<1$ & 1.041 & $<10$ & $\begin{array}{l}\text { Tidak ada } \\
\text { multikolinieritas }\end{array}$ \\
\hline $\begin{array}{l}\text { Kualitas Pelayanan } \\
\left(\mathrm{X}_{2}\right)\end{array}$ & 0.960 & $<1$ & 1.041 & $<10$ & $\begin{array}{l}\text { Tidak ada } \\
\text { multikolinieritas }\end{array}$ \\
\hline
\end{tabular}

Sumber : Data Primer, tahun 2018 yang telah diolah dengan SPSS versi 22

Berdasarkan tabel pengujian multikolinieritas di atas diperoleh nilai Variance Inflation Factor (VIF) masing-masing variabel bebas memiliki nilai toleransi $<1$ dan nilai VIF $<10$, dengan demikian model regresi ini tidak ada multikolinearitas.

Tabel 4.6

\section{Pedoman Interpretasi Uji Durbin-Watson}

\begin{tabular}{|c|c|}
\hline Kriteria & Keterangan \\
\hline$<1$ & Ada autokorelasi \\
\hline $1,1-1,54$ & Tanpa kesimpulan \\
\hline $1,55-2,46$ & Tidak ada autokorelasi \\
\hline $2,46-2,9$ & Tanpa kesimpulan \\
\hline$>2,9$ & Ada autokorelasi \\
\hline
\end{tabular}

Sumber : Sugiyono (2012:184)

Tabel 4.8

Uji Durbin-Watson

Model Summary ${ }^{b}$

\begin{tabular}{|l|r|r|r|r|r|r|}
\hline Model & \multicolumn{1}{|c|}{$\mathrm{R}$} & \multicolumn{1}{|c|}{ R Square } & $\begin{array}{c}\text { Adjusted R } \\
\text { Square }\end{array}$ & $\begin{array}{c}\text { Std. Error } \\
\text { of the } \\
\text { Estimate }\end{array}$ & $\begin{array}{c}\text { Durbin- } \\
\text { Watson }\end{array}$ & Keterangan \\
\hline 1 & $.758^{\mathrm{a}}$ & .575 & .564 & 2.719 & 1.923 & $\begin{array}{c}\text { Tidak ada } \\
\text { autokorelasi }\end{array}$ \\
\hline
\end{tabular}

Sumber : Data Primer, tahun 2018, diolah

Nilai Durbin-Watson sebesar 1.923 yang berada diantara $1.550-2.460$. 


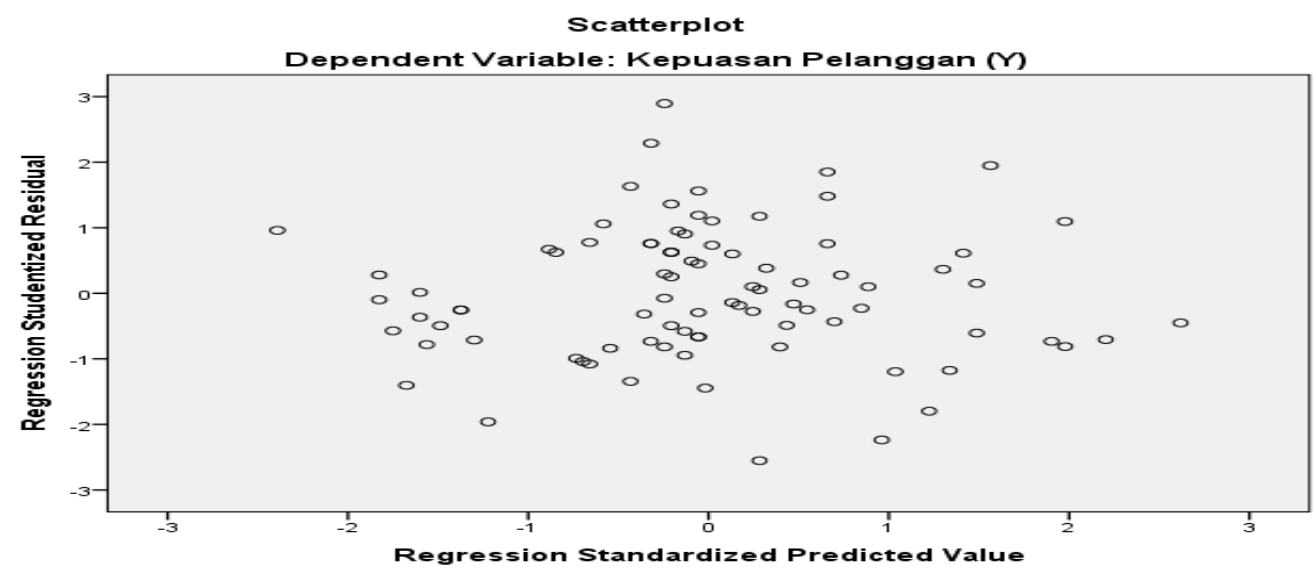

Sumber : Data Primer, tahun 2018, diolah dengan SPSS Versi 22

Gambar 4.2

Grafik Scatter Plot Hasil Uji Heteroskedastisitas

Analisis Regresi Linier Berganda

Tabel 4.9

Hasil Pengolahan Regresi Berganda Variabel Kualitas Produk $\left(X_{1}\right)$ dan Kualitas Pelayanan $\left(X_{2}\right)$

\begin{tabular}{|c|c|c|c|c|c|c|}
\hline \multirow{2}{*}{\multicolumn{2}{|c|}{ Model }} & \multicolumn{2}{|c|}{$\begin{array}{c}\text { Unstandardized } \\
\text { Coefficients }\end{array}$} & $\begin{array}{l}\text { Standardized } \\
\text { Coefficients }\end{array}$ & \multirow[t]{2}{*}{$\mathrm{T}$} & \multirow[t]{2}{*}{ Sig. } \\
\hline & & $\mathrm{B}$ & $\begin{array}{l}\text { Std. } \\
\text { Error }\end{array}$ & Beta & & \\
\hline \multirow{3}{*}{1} & (Constant) & 7.606 & 3.625 & & 2.098 & .039 \\
\hline & KualitasProduk (X1) & .588 & .062 & .691 & 9.465 & .000 \\
\hline & KualitasPelayanan (X2) & .236 & .085 & .202 & 2.768 & .007 \\
\hline
\end{tabular}

Sumber : Data Primer tahun 2018, (diolah)

\section{Pengaruh Secara Parsial.}

Untuk mengetahui pengaruh variabel kualitas produk $\left(X_{1}\right)$ dan kualitas pelayanan $\left(\mathrm{X}_{2}\right)$ terhadap kepuasan pelanggan $(\mathrm{Y})$ secara parsial, digunakan analisis koefisien korelasi dan koefisien determinasi. Adapun persentase tingkat hubungan secara parsial tersebut hasil analisisnya sebagai berikut: 
Tabel 4.10

Pengaruh Secara Parsial Variabel Kualitas Produk $\left(X_{1}\right)$ Terhadap Kepuasan Pelanggan (Y)

Model Summary

\begin{tabular}{|l|r|r|r|r|}
\hline Model & $\mathrm{R}$ & $\mathrm{R}$ Square & \multicolumn{1}{|c|}{$\begin{array}{c}\text { Adjusted R } \\
\text { Square }\end{array}$} & Std. Error of the Estimate \\
\hline 1 & $732 .^{\mathrm{a}}$ & .535 & 530 & 2.825 \\
\hline
\end{tabular}

a. Predictors: (Constant), Kualitas Produk (X1)

1 Sumber : Data Primer tahun 2018, diolah.

Berdasarkan tabel di atas, diperoleh nilai $R$-square (koefisien determinasi) sebesar 0,535 maka dapat disimpulkan bahwa variabel kualitas produk $\left(\mathrm{X}_{1}\right)$ berpengaruh terhadap variabel kepuasan pelanggan ( $Y$ ) sebesar 53,5\% sedangkan sisanya $46,5 \%$ dipengaruhi oleh faktor lain.

Tabel 4.11

Pengaruh Secara Parsial Variabel Kualitas Pelayanan $\left(\mathbf{X}_{\mathbf{2}}\right)$ Terhadap Kepuasan Pelanggan (Y)

\begin{tabular}{|l|r|r|r|r|}
\hline Model & $\mathrm{R}$ & $\mathrm{R}$ Square & \multicolumn{1}{c|}{$\begin{array}{c}\text { Adjusted } \mathrm{R} \\
\text { Square }\end{array}$} & Std. Error of the Estimate \\
\hline 1 & $.340^{\mathrm{a}}$ & .116 & .105 & 3.897 \\
\hline
\end{tabular}

a. Predictors: (Constant), Kualitas Pelayanan (X2)

Sumber : Data Primer tahun 2018, diolah.

Nilai $R$-square (koefisien determinasi) sebesar 0,116 maka dapat disimpulkan bahwa variabel kualitas pelayanan $\left(\mathrm{X}_{2}\right)$ berpengaruh terhadap variabel kepuasan pelanggan $(Y)$ sebesar $11,6 \%$ sedangkan sisanya $88,4 \%$ dipengaruhi oleh faktor lain.

Analisis Koefiisien Korelasi dan Determinasi (Secara Simultan)

Tabel 4.12

Hasil Pengolahan Data Korelasi dan Koefiisien Determinasi Variabel

Kualitas Produk $\left(\mathrm{X}_{1}\right)$ dan Kualitas Pelayanan $\left(\mathrm{X}_{2}\right)$

Model Summary

\begin{tabular}{|l|r|r|r|r|}
\hline Model & R & R Square & \multicolumn{1}{|c|}{$\begin{array}{c}\text { Adjusted R } \\
\text { Square }\end{array}$} & $\begin{array}{c}\text { Std. Error of the } \\
\text { Estimate }\end{array}$ \\
\hline 1 & $.758^{\mathrm{a}}$ & .575 & .564 & 2.719 \\
\hline
\end{tabular}

a. Predictors: (Constant), Kualitas Pelayanan (X2),Kualitas Produk (X1) 
Sumber : Data Primer tahun 2018, diolah dengan SPSS Versi 22.

Berdasarkan tabel di atas, diperoleh nilai $\mathrm{R}$ Korelasi sebesar 0,758 yang berarti hubungan antar variabel bebas dan terikat kuat. $R$-square (koefisien determinasi) sebesar 0,575 maka dapat disimpulkan bahwa variabel kualitas produk $\left(\mathrm{X}_{1}\right)$ dan kualitas pelayanan $\left(\mathrm{X}_{2}\right)$ berkontribusi terhadap variabel kepuasan pelanggan (Y) pada PT. Radekatama Piranti Nusa sebesar $57,5 \%$ sedangkan sisanya $42,5 \%$ dipengaruhi oleh faktor lain.

\section{Uji Hipotesis $\mathbf{t}$}

Pengaruh Kualitas Produk $\left(\mathrm{X}_{1}\right)$ Terhadap Kepuasan Pelanggan ( $\mathrm{Y}$ )

Tabel 4.13

Hasil Uji t Variabel Kualitas Produk $\left(X_{1}\right)$

\begin{tabular}{|c|c|c|c|c|c|c|}
\hline \multirow{2}{*}{\multicolumn{2}{|c|}{ Model }} & \multicolumn{2}{|c|}{$\begin{array}{c}\text { Unstandardized } \\
\text { Coefficients }\end{array}$} & \multirow{2}{*}{$\begin{array}{c}\begin{array}{l}\text { Standardized } \\
\text { Coefficients }\end{array} \\
\text { Beta }\end{array}$} & \multirow[t]{2}{*}{$\mathrm{T}$} & \multirow[t]{2}{*}{ Sig. } \\
\hline & & B & Std. Error & & & \\
\hline \multirow[b]{2}{*}{1} & (Constant) & 15.281 & 2.426 & & 6.299 & .000 \\
\hline & $\begin{array}{l}\text { KualitasProduk } \\
\text { (X1) }\end{array}$ & .622 & .063 & .732 & 9.840 & .000 \\
\hline
\end{tabular}

Sumber : Data Primer tahun 2018, diolah dengan SPSS Versi 22

Berdasarkan tabel di atas diperoleh nilai $t_{\text {hitung }}>t_{\text {tabel }}(9.840>1.989)$, hal itu juga dibuktikan dengan signifikansi $0,000<0,05$. Dengan demikian maka $\mathrm{H}_{0}$ ditolak dan $\mathrm{H}_{1}$ diterima, hal ini menunjukkan bahwa terdapat pengaruh yang positif dan signifikan secara parsial antara kualitas produk terhadap kepuasan pelanggan pada PT. Radekatama Piranti Nusa.

\section{Pengaruh Kualitas Pelayanan $\left(\mathrm{X}_{2}\right)$ Terhadap Kepuasan Pelanggan (Y) Tabel 4.14}

Hasil Uji t Variabel Kualitas Pellayanan $\left(\mathrm{X}_{2}\right)$

\begin{tabular}{|l|r|r|r|r|r|}
\hline Model & \multicolumn{2}{|c|}{$\begin{array}{c}\text { Unstandardized } \\
\text { Coefficients }\end{array}$} & $\begin{array}{c}\text { Standardize } \\
\text { d } \\
\text { Coefficients }\end{array}$ & T & Sig. \\
\cline { 2 - 5 } & B & Std. Error & Beta & 5.214 & .000 \\
\hline $\begin{array}{l}\text { (Constant) } \\
\text { KualitasPelayan } \\
\text { an (X2) }\end{array}$ & 23.859 & 4.576 & & 3.315 & .001 \\
\hline
\end{tabular}

Sumber : Data Primer tahun 2018, diolah dengan SPSS Versi 22 
Berdasarkan tabel di atas diperoleh nilai $t_{\text {hitung }}>t_{\text {tabel }}(3.315>1.989)$, hal itu juga dibuktikan dengan signifikansi $0,000<0,05$. Dengan demikian maka $\mathrm{H}_{0}$ ditolak dan $\mathrm{H}_{1}$ diterima, hal ini menunjukkan bahwa terdapat pengaruh yang positif dan signifikan secara parsial antara kualitas pelayanan terhadap kepuasan pelanggan pada PT. Radekatama Piranti Nusa.

\section{Pengujian Hipotesis Secara Simultan (Uji F).}

\section{Tabel 4.15 \\ Hasil Uji F Simultan ANOVA $^{\mathrm{a}}$}

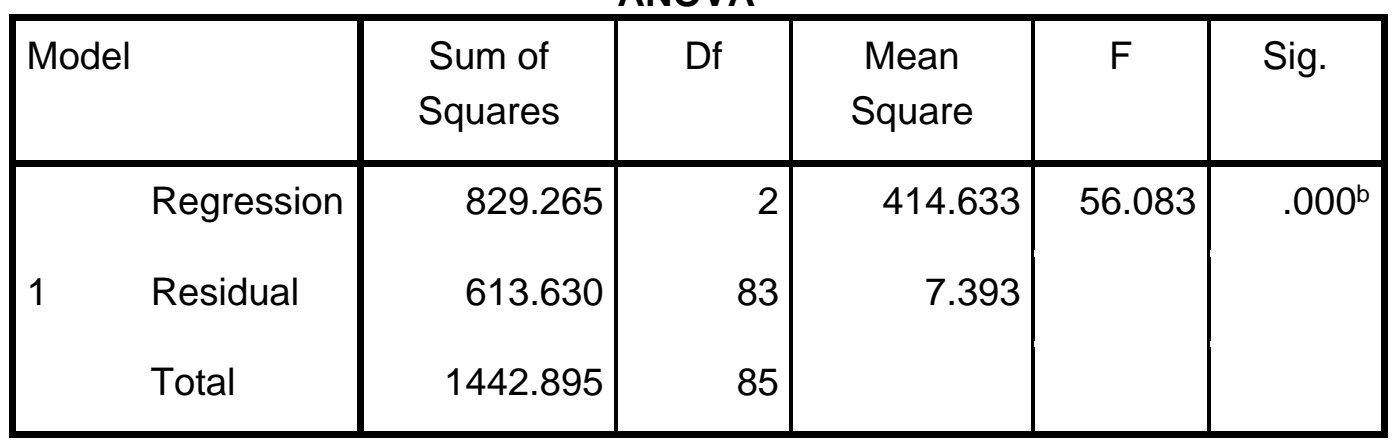

a. Dependent Variable: KepuasanPelanggan (Y)

b. Predictors: (Constant), KualitasPelayanan (X2), KualitasProduk (X1)

Sumber : Data Primer tahun 2018, (diolah)

Dari tabel di atas, diperoleh nilai $\mathrm{F}$ hitung lebih besar dari $\mathrm{F}$ tabel atau $(56,083>3,110)$, hal tersebut juga diperkuat dengan signifikansi $0,000<0,05$. Dengan demikian $\mathrm{H}_{0}$ ditolak dan $\mathrm{H}_{1}$ diterima. Artinya terdapat pengaruh positif dan signifikan secara simultan antara kualitas produk dan kualitas pelayanan terhadap kepuasan pelanggan pada PT. Radekatama Piranti Nusa.

\section{Kesimpulan}

Berdasarkan uraian pada bab-bab sebelumnya, dan dari hasil analisis serta pembahasan mengenai pengaruh kualitas produk dan kualitas pelayanan terhadap kepuasan pelanggan, sebagai berikut :

1. Dari pengujian hipotesis diperoleh t nilai $t_{\text {hitung }}>t_{\text {tabel }}(6,118>1,985)$, hal itu juga dibuktikan dengan signifikansi 0,000 <0,05. Dengan demikian maka $\mathrm{H}_{0}$ ditolak dan $\mathrm{H}_{1}$ diterima, hal ini menunjukkan bahwa terdapat pengaruh yang positif dan signifikan secara parsial antara kualitas produk terhadap Kepuasan pelanggan.

2. Dari pengujian hipotesis diperoleh $t$ hitung nilai $t_{\text {hitung }}>t_{\text {tabel }}(7,645>1,985)$, hal itu juga dibuktikan dengan signifikansi $0,000<0,05$. Dengan demikian maka $\mathrm{H}_{0}$ ditolak dan $\mathrm{H}_{1}$ diterima, hal ini menunjukkan bahwa terdapat pengaruh yang positif dan signifikan secara parsial antara kualitas pelayanan terhadap kepuasan pelanggan.

3. Berdasarkan hasil penelitian, menunjukkan bahwa kualitas produk dan kualitas pelayanan berpengaruh positif terhadap kepuasan pelanggan dengan persamaan regresi $Y=15,009+0,294 X_{1}+0,422 X_{2}$. Kontribusi pengaruh kualitas produk, kualitas pelayanan dan kepuasan pelanggan secara simultan 
adalah sebesar $44,8 \%$ sedangkan sisanya sebesar $55,2 \%$ dipengaruhi faktor lain. diperoleh nilai $F$ hitung lebih besar dari $F$ tabel atau $(39,285>2,700)$, hal tersebut juga diperkuat dengan signifikansi $0,000<0,05$. Dengan demikian $\mathrm{H}_{0}$ ditolak dan $\mathrm{H}_{1}$ diterima. Artinya terdapat pengaruh positif dan signifikan secara simultan antara kualitas produk dan kualitas pelayanan terhadap kepuasan pelanggan.

\section{Saran}

1. Perusahaan harus meningkatkan mutu produk dengan memperhatikan timbangan berat tabung dan pemasangan seal cap serta kerapihan dan keamanan tabung $\mathrm{lpg} 3 \mathrm{~kg}$.

2. Perusahaan harus lebih memperhatikan kualiatas pelayanan berupa ketanggapan dan ketepatan informasi yang diberikan serta mampu menanggapi keluhan pelanggan dengan ramah dan sigap.

\section{G. Daftar Pustaka}

Aaker, A, 2004. "Manajemen Ekuitas Merek Memanfaatkan Nilai dari Suatu Merek". Edisi Pertama. Mitra Utama, Jakarta.

Algifari, 2010, "Analisis Regresi”, Yogyakarta, 2010.

Alma, Buchori, "Manajemen Pemasaran \& Pemasaran Jasa", CV. Alfabetha, Bandung, 2009.

Angipora Marius P. "Dasar-Dasar Pemasaran", PT. Raja Grafindo Persada, Jakarta, 2012.

Arikunto, Suharsimi, "Prosedur Penelitian Suatu Pendekatan Praktek", PT. Rineka Cipta, Jakarta, 2010.

Assauri, Sofian, "Manajemen Produksi Dan Operasi", LPFE Universitas Indonesia, Jakarta, 2012.

Chandra, Gregorius, "Strategi Dan Program Pemasaran”, Andi Offset, Yogyakarta, 2011.

David W.Craven "Strategic Marketing", Mc-Graw Hill International, 2014.

G.R. Terry, \& Rue, Leslie W. Rue, "Dasar-dasar Manajemen", Bumi Aksara, Jakarta 2010.

Ghozali, Imam, "Aplikasi Analisis Multivariate dengan Program SPSS", Edisi Kelima, Badan Penerbit Undip, Semarang, 2011

Griffin, Jill. 2012. "Customer Loyalty: How to Earn It, How to Keep It". Simon and Chuster. Inc. New York.

Hasan, Ali. 2013. "Marketing". Media Utama., Yogyakarta.

Hasibuan, SP, “Dasar-dasar Perbankan”, Haji Masagung, Jakarta, 2012.

Hurriyati, Ratih, "Bauran Pemasaran Dan Loyalitas Konsumen", CV. Alfabetha, Bandung, 2012.

Keller dan Amstrong, "Prinsip-prinsip Pemasaran”, Edisi Kedua Belas, Jilid Satu, Erlangga, Jakarta, 2012

Kotler, Philip, “Manajemen Pemasaran”, Edisi Keempat belas, PT. Indeks, Jakarta, 2012.

Laksana, Fajar, “Manajemen Pemasaran”, Edisi Pertama, Graha Ilmu, Yogyakarta, 2013

Lovelock \& Wright, "Principle of Services Marketing And Management", Prentice Hall Inc., Upper Saddle River, New Jersey, USA, 2011. 
M.F.Shellyana J \& H.Hidayat, "Hubungan Antara Persepsi Harga Konsumen Dan Konsep Pemasaran Terhadap Produk Merk Toko", Dalam Jurnal Ekonomi Pembangunan, Jakarta, 2012.

Malayu S.P Hasibuan, "Dasar-dasar Perbankan", Haji Masagung, Jakarta, 2012.

Marknesis, Tim, "Customer Satisfaction and Beyond", Marknesi, Yogyakarta, 2012.

Peraturan Menteri Perindustrian Republik Indonesia Nomor : 02/M-IND/PER/2009 membuat regulasi tentang pemberlakuan Wajib Standar Nasional Indonesia (SNI).

Peraturan Presiden Republik Indonesia Nomor: 28 tahun 2008 tentang kebijakan industri nasional

Safroni, Ladzi, "Manajemen dan Reformasi Pelayanan Publik dalam Konteks Birokrasi Indonesia", Aditya Media Publishing, Surabaya 2012.

Saladin, Djaslim, "Manajemen Pemasaran", Linda Karya, Bandung, 2012.

Sarwono, Jonathan, "Metode Penelitian Kuantitatif Dan Kualitatif", Graha IImu, Yogyakarta, 2012

Singgih Santoso, "SPSS Statistik Parametik" Cetakan Kedua, PT. Elek Media

Sugiyono, "Metode Penelitian Kuantitatif Kualitatif dan $R$ \& D", Penerbit CV. Alfabeta, Bandung, 2014.

Sugiyono, "Metode Penelitian Kuantitatif Kualitatif dan $R \& D$ ", Penerbit CV. Alfabeta, Bandung, 2012.

Swastha, Bashu dan T. Handoko, "Manajemen Pemasaran Moderen", BPFE, Yogyakarta, 2010..

Syofian Siregar, "Statistika Deskriptif Untuk Penelitian”, PT Raja Grafindo Persada, Jakarta, 2010.

Tjiptono, Fandy dan Gregorius Chandra, "Serivce Quality and Satisfiation", Edisi tiga, Andi, Jakarta, 2012.

Udang-undang Nomor 5 Tahun 1984 tentang industri

Umar, Husen, "Riset Pemasaran Dan Perilaku Konsumen”, PT. Gramedia Pustaka Utama, Jakarta , 2013.

Usmara, "Strategi Baru Manajemen Pemasaran", Amoro book, Yogyakarta, 2013.

Wawan S. Suherman, "Kurikulum Berbasis Kompetensi Pendidikan Jasmani Teori dan Praktik Pengembangan", FIK UNY, Yogyakarta, 2012

Wiliam J. Stanton, "Prinsip-Prinsip Pemasaran”, Edisi ketujuh, Erlangga, Jakarta, 2010.

Zeithaml \& Bitner, "Service Marketing", McGraw Hill Companies, Singapore, 2013.

Zimmerer, TW dan Scarborough, NM, "Essential of Entrepreneur and Small Business Management", 2th, Prentice Hal. 2011.

Kotler, Philip Dan Gary Amstrong, "Prinsip-Prinsip Pemasaran", Edisi 12, jilid 1, Erlangga, Jakarta, 2008.

Tjiptono, Fandy. "Strategi Pemasaran", Edisi ke-3, CV Andi Offset, Yogyakarta, 2008.

Anwar,Iful,"Skripsi: Pengaruh Harga dan Kualitas Produk Terhadap Keputusan Pembelian", Sekolah Tinggi IImu Ekonomi Indonesia (STIESIA) Surabaya, 2015

Setiawati,Bekti,"Skripsi: Pengaruh Kualitas Produk dan Harga Terhadap Keputusan Pembelian", Universitas Negeri Semarang (UNNES), 2006

Luqman,lqbal"Skripsi: Pengaruh Kualitas Produk,Harga,Promosi Terhadap Keputusan Pembelian", Universitas Islam Negeri Sunan Kalijaga Yogyakarta, 2015 
Evelina, N., Wiratno dan S. Listyorini. Pengaruh Citra Merek, Kualitas Produk, Harga, dan Promosi Terhadap Keputusan Pembelian Kartu Perdana TelkomFlexi, Fakultas IImu Sosial dan IImu Politik, Jurusan Administrasi Bisnis Universitas Diponegoro, Semarang, 2012

Nurhadi. Pengaruh Kualitas Produk Dan Harga Terhadap Keputusan Pembelian Polyfoam Pada PT Beta Sinarindo, Fakultas Ekonomi, Universitas Pamulang, Tangerang Selatan 2016

Zainal, Fadly. Pengaruh Kualitas Produk Terhadap Keputusan Pembelian Cat Semprot RJ London Chemchal Pada PT Mega Jaya Net, Fakultas Ekonomi, Universitas Pamulang, Tangerang Selatan 2016

Sutrisno, Andik. Pengaruh Kualitas Produk, Harga Dan Kualitas Pelayanan Terhadap Kepuasan Pelanggan Pada PT Bisma Narendra, Fakultas Ekonomi, Universitas Pamulang, Tangerang Selatan 2017.

Fahmi, Adzi, A. Pengaruh Kualitas Produk Dan Harga Terhadap Keputusan Pembelian Smartphone Pada Samsung Store Mall Bintaro Xchange, Fakultas Ekonomi, Universitas Pamulang, Tangerang Selatan 2017.

Internet:

- http://simki.unpkediri.ac.id/mahasiswa/file artikel/2015/11.1.02.02.0375.pd $\mathrm{f} / 12.10 / 18 / 09 / 2017$

- http://eprints.uny.ac.id/27207/1/AdityaSulisMartopo 12808142003.pdf/12.1 1/18/09/2017

- $\quad$ https://ejournal.unsrat.ac.id/index.php/emba/article/view/2576/2108/17.05 wib 26/09/17

- $\quad$ https://scholar.google.co.id/scholar?start=40\&q=pengaruh+kualitas+produ $\mathrm{k}$ +terhadap+loyalitas+pelanggan\&hl=en\&as $\mathrm{sdt}=0,5 \&$ as ylo=2010\&as yhi $=2015 / 17.06 \mathrm{wib} / 26 / 09 / 2017$

- http://harga.link/kesehatan/kumpulan-daftar-harga-propolis-saatini/20.00wib/7/12/2017

- https://propolisdiamon.wordpress.com/2010/06/05/pengertian propolis/31/03/18/15:15wib

- https://repository.widyatama.ac.id/xmlui/bitstream/handle/123456789/4626 Bab\%202.pdf?sequence=10/4/06/2018/19:30wib

- https://www.researchgate.net/publication/322692375 Pengaruh harga ku alitas produk dan distribusi terhadap keputusan pembelian/4/06/2018/1 9:30wib 